\title{
ASPECTOS ETNOBOTÁNICOS, NUTRICIONALES Y ACTIVIDAD BIOLÓGICA DE EXTRACTOS DE FRUTOS DEL GÉNERO Bromelia
}

\section{ETHNOBOTANICAL AND NUTRITIONAL ASPECTS, AND BIOLOGICAL ACTIVITY OF FRUIT EXTRACTS OF THE GENUS Bromelia}

\section{Libier Meza-Espinoza', Ma. de Lourdes García-Magaña', Ma. de los Ángeles Vivar-Vera², Sonia G. Sáyago-Ayerdi', Alejandra Chacón-López', Eduardo M. Becerra-Verdín, Ma. Dolores Muy-Rangel ${ }^{4}$ y Efigenia Montalvo-González ${ }^{1}$ *}

\begin{abstract}
'Laboratorio Integral de Investigación en Alimentos, Instituto Tecnológico de Tepic. Av Tecnológico No. 2595. 63175, Lagos del Country. Tepic, Nayarit. ${ }^{2}$ Instituto Tecnológico de Tuxtepec. Av. Dr. Víctor Bravo Ahuja S/N. 68350, Col. 5 de Mayo. Tuxtepec, Oax. ${ }^{3}$ Unidad Académica de Ciencias Químicas Biológicas y Farmacéuticas, Universidad Autónoma de Nayarit. Ciudad de la Cultura Amado Nervo S/N. 63155, Los Frenos, Tepic Nayarit. ${ }^{4}$ Centro de Investigación en Alimentación y Desarrollo A. C. km 5.5. Carr. a Eldorado. 80110, Campo el Diez, Culiacán, Sinaloa.
\end{abstract}

*Autor para correspondencia (efimontalvo@gmail.com)

\section{RESUMEN}

Las plantas del género Bromelia se distribuyen en América Latina, especialmente en las regiones del pacífico y Golfo de México; tienen usos diversos ya sea como plantas de ornato, plantas medicinales 0 alimento. Los frutos de estas especies son de tipo baya y se desarrollan constituyendo una infrutescencia de color amarillo o rosado de forma alargada u ovalada. Desde el punto de vista nutricional estos frutos tienen gran potencial ya que son buena fuente de minerales como calcio, potasio y fósforo; además, contienen vitamina $\mathrm{C}$ y son ricos en cisteína proteasas. Desde tiempos prehispánicos los frutos de estas especies se utilizaban en la medicina tradicional para tratar enfermedades respiratorias y trastornos del sistema urinario, entre otras. Hoy en día, las investigaciones demuestran que los extractos de la pulpa de frutos tienen actividad antimicrobiana, antihelmíntica, antitumoral y antiinflamatoria, cuyos efectos son atribuidos a metabolitos secundarios (fenoles, saponinas terpenoides, etc.) y cisteína proteasas. Las enzimas proteolíticas caracterizadas en estos frutos son similares a las proteasas vegetales comerciales y pueden ser una alternativa potencial en la industria alimentaria y farmacéutica. En esta revisión se dan a conocer los usos etnobotánicos, características nutricionales, actividad biológica y estudios tecnológicos reportados en extractos de frutos del género Bromelia.

Palabras clave: Bromelia, frutos, etnobotánica, características nutricionales, actividad biológica, estudios tecnológicos.

\section{SUMMARY}

Plants of the Bromelia genus are distributed in Latin America, particularly in regions of the Pacific and Gulf of Mexico. These plants are used as ornaments medicines or food. These species produce berry-type fruits that develop by creation of a yellow or reddish, elongated or oval infructescence. From the nutritional perspective, these fruits have great potential as a good source of minerals like calcium, potassium and phosphorous, as well as vitamin $\mathrm{C}$ and cysteine proteases. Since pre-Hispanic times, the fruits of these species were used in traditional medicine to treat respiratory diseases and disorders of the urinary system, among others. Current research shows that extracts from fruit pulp have antimicrobial, anthelmintic, anti-tumor and anti-inflammatory activity, and these effects are attributed to secondary metabolites (phenols, saponins and terpenoids, etc.) and cysteine proteases. The proteolytic enzymes characterized in these fruits are similar to commercial plant proteases, and might be a potential alternative in the food and pharmaceutical industry.
In this review we present the ethnobotanical uses, nutritional characteristics, biological activity and technological studies reported in extracts of fruits of the genus Bromelia.

Index words: Bromelia, fruits, ethnobotany, nutritional characteristics, biological activity, technological studies.

\section{INTRODUCCIÓN}

La familia Bromeliaceae incluye el género Bromelia, integrado por plantas con relevancia ecológica por su grado de endemismo y relación con la fauna de su hábitat. Estas plantas son originarias de la zona neotropical y tropical, y se producen en gran parte de América Latina (Hornung-Leoni, 2011a; Martinelli et al., 2008).

La producción de Bromelia en México se localiza desde Sonora hasta Guerrero por la parte del Pacífico y desde Veracruz hasta Yucatán por la región del Golfo (Espejo-Serna et al., 2004). Los frutos se consumen en fresco y procesados en bebidas, infusiones y en almíbar; además, se emplean en ceremonias de carácter religioso, como plantas de ornato y en la preparación artesanal de medicina naturista (Hornung-Leoni, 2011b).

Algunos frutos de Bromelia se caracterizan por ser una buena fuente de ácido ascórbico (e.g. Bromelia pinguin L. con $126 \mathrm{mg} 100 \mathrm{~g} \mathrm{~g}^{-1}$ ) y minerales como calcio, potasio y magnesio (Abreu et al., 2005a; Moyano et al., 2012; PíoLeón et al., 2009), siendo reconocidas por su alto contenido de cisteína proteasas (Abreu et al., 2001; 2005a).

En la industria, las proteasas obtenidas de frutos del género Bromelia se han reportado como efectivas para la producción de hidrolizados proteicos (Briones-Martínez et al., 1994). Adicionalmente, los extractos obtenidos de 
los frutos también han sido estudiados con respecto a su efecto citotóxico, antihelmíntico y antimicrobiano (Abreu et al., 2001, Abreu et al., 2005a), anti-inflamatorio (Errasti et al., 2013) y anti-tumoral (Guimarães-Ferreira et al., 2007).

Las aplicaciones más recientes de algunas de estas proteasas son en la obtención de péptidos bioactivos, los cuales se caracterizan por ejercer un importante papel en la regulación y la modulación metabólica en los seres humanos (Bruno et al., 2010; Pardo et al., 2001; Prospitti et al., 2015). Por todo lo anterior, el objetivo de esta revisión es dar a conocer los aspectos etnobotánicos, nutricionales, actividad biológica y estudios tecnológicos de frutos del género Bromelia, a fin de continuar con investigaciones futuras para conferirles mayor valor agregado y en un futuro puedan ser aprovechados como un recurso biológico alternativo en la industria de alimentos, farmacéutica o medicina natural.

\section{DISTRIBUCIÓN DE LA FAMILIA BROMELIACEAE}

Las bromeliáceas pertenecen a uno de los grupos taxonómicos más relevantes dentro de su hábitat (bosques) debido a su alto grado de endemismo. Son de gran importancia ecológica por su estrecha relación con la fauna local (Martinelli et al., 2008).

La familia consta de aproximadamente 3172 especies repartidas en tres subfamilias: Pitcairnioideae, Bromelioideae y Tillandsioideae y en 58 géneros, los cuales se localizan en México, Belice, Guatemala, Panamá, las Antillas y el norte de Sudamérica y una sola especie se ubica en el oeste de África (Espejo-Serna et al., 2004). México se constituye como un centro de diversificación de la subfamilia Bromelioideae ya que se han registrado 18 géneros y 342 especies (Espejo-Serna et al., 2004). Específicamente, en relación con el género Bromelia, las especies habitan en clima cálido desde el nivel del mar y hasta los 200 m de altitud, asociadas a dunas costeras y bosque tropical caducifolio (Espejo-Serna et al., 2004).

\section{DESCRIPCIÓN BOTÁNICA DE PLANTAS DE Bromelia}

El género Bromelia está representado por especies tanto terrestres como epífitas, con margen foliar serrado, ovario ínfero, fruto tipo baya y semillas desnudas (Espejo-Serna et al., 2004; 2005). En el género se incluyen más de 60 especies, pero pocas de ellas han sido descritas botánicamente y reconocidas por producir frutos comestibles (Cuadro 1).

Las especies de Bromelia son plantas arbustivas con hojas numerosas en forma de roseta, erguidas, de 1 a 3 $\mathrm{m}$ de largo y de 2 a $4 \mathrm{~cm}$ de ancho, el borde con espinas curvas de 5 a $10 \mathrm{~mm}$ y cambian de color verde brillante a rojo (Espejo-Serna et al., 2004). Asimismo, se les describe como plantas estoloníferas con filodios envainadores de $1.5 \mathrm{~m}$ de largo por $4 \mathrm{~cm}$ de ancho, con bordes muy espinosos, punta muy prolongada y punzante; poseen merítalos cortos ( $40 \mathrm{~cm}$ de largo x $1.5 \mathrm{~cm}$ de diámetro) en cuyo extremo desarrollan una infrutescencia (Caffini et al 1988; González-Salvatierra et al., 2013). La posición de la roseta o infrutescencia en relación con el eje central durante la floración es de aproximadamente $45^{\circ}$. Asimismo, se presentan brácteas del pedúnculo durante la antesis, brácteas florales iguales o superiores al ovario, y no presentan sépalos. Las flores poseen pétalos carnosos, crecen en grupo en un eje corto y los pétalos miden alrededor de $3 \mathrm{~cm}$ (Espejo-Serna et al., 2004; Monteiro et al., 2015).

Los frutos son de color amarillo o color rosado, con estomas marcados en la epidermis, haces vasculares de diámetro pequeño, más alto que ancho. Los frutos son carnosos y con semillas aplanadas (Espejo-Serna et al., 2004). Las especies del género Bromelia comparten muchas características morfológicas; sin embargo, mantienen diferencias importantes entre las que destacan color, forma y tamaño de los frutos (Cuadro 1). En la Figura 1 se muestran las plantas y frutos de las especies $B$. pinguin L. (Figura 1a) y B. karatas L. (Figura 1b) encontradas en el municipio de Santiago Ixcuintla, Nayarit, y son también las dos especies mayormente distribuidas en México.

\section{COMPOSICIÓN NUTRICIONAL DE LOS FRUTOS DE Bromelia}

La caracterización nutricional de los frutos de Bromelia hasta ahora es escasa, ya que sólo tres de 11 especies frutícolas identificadas se han caracterizado. Las investigaciones reportadas se citan en el Cuadro 2. La pulpa de frutos de B. pinguin L. cultivada en Cuba presentó una cantidad importante de proteínas, así como de los minerales calcio, magnesio, potasio, sodio y fósforo (Abreu et al. 2005a). En frutos de la misma especie, pero cultivados en Sinaloa, México, Pío-León et al. (2009) reportaron que los frutos están compuestos de $80 \%$ de porción comestible y $20 \%$ de cáscara, son frutos ácidos, con pH de 3.7, acidez titulable de $4.6 \%$ y sólidos solubles totales de $14.1 \%$. Tienen un contenido de vitamina $\mathrm{C}$ de $126 \mathrm{mg} 100 \mathrm{~g}^{-1}$, más alto que lo reportado para algunos cítricos (30 a $57 \mathrm{mg} 100$ $\mathrm{g}^{-1}$ ), Actinidia deliciosa (98 mg $57 \mathrm{mg} 100 \mathrm{~g}^{-1}$ ) y Litchi chinensis (71.5 mg $100 \mathrm{~g}^{-1}$ ) (Ledesma et al., 2010).

Los frutos de B. pinguin $L$. son considerados con alto valor nutricional en relación con su contenido de minerales, ya que $100 \mathrm{~g}$ de la pulpa del fruto aportan la ingesta recomendada de calcio (1300 mg), magnesio $(420 \mathrm{mg})$ y manganeso (2.3 mg), para personas adultas (FDA, 2001; 
Cuadro 1. Descripción botánica de frutos de Bromelias.

\begin{tabular}{|c|c|c|c|}
\hline Especie & Nombre común & Descripción botánica de frutos & Referencia \\
\hline Bromelia alsodes H.St.John & $\begin{array}{l}\text { Cucuya, hijo de piña, } \\
\text { mutate, piñuela, polla (El } \\
\text { Salvador). }\end{array}$ & $\begin{array}{l}\text { Infrutescencias paniculadas de } 25 \mathrm{~cm} \\
\text { de largo. Frutos de } 2 \mathrm{~cm} \text { de diámetro, } \\
\text { subglobosos, de color amarillo cuando son } \\
\text { maduros y con pocas semillas. }\end{array}$ & Chízmar (2009) \\
\hline Bromelia antiacantha Berthol. & $\begin{array}{l}\text { Banana-do-mato o } \\
\text { banana silvestre (Brasil). }\end{array}$ & $\begin{array}{l}\text { Infrutescencias centrales. Frutos maduros } \\
\text { tienen un color amarillo-naranja y la forma } \\
\text { es como un plátano pequeño. }\end{array}$ & $\begin{array}{l}\text { Díaz y Delascio-Chitty } \\
\text { (2007); Fabri y da } \\
\text { Costa (2012) }\end{array}$ \\
\hline Bromelia crhysantha Jacq. & Piñuela (México). & $\begin{array}{l}\text { Hierba litófila de } 1-1.5 \mathrm{~m} \text { de alto. Frutos } \\
\text { verdes, envés grisáceo, con una pelusa } \\
\text { color marrón. }\end{array}$ & $\begin{array}{l}\text { Díaz y Delascio-Chitty } \\
\text { (2007); Chan-Quijano } \\
\text { et al. (2013) }\end{array}$ \\
\hline Bromelia fastuosa Lindl. & Gravatá (Brasil). & $\begin{array}{l}\text { Frutos de color verde con cambio en } \\
\text { color amarillo cuando maduran, forma } \\
\text { subglobosa con } 2-3 \mathrm{~cm} \text { de diámetro. }\end{array}$ & Cabral et al. (2006) \\
\hline $\begin{array}{l}\text { Bromelia karatas L., o Bromelia } \\
\text { plumieri (E. Morren). L.B. Sm. }\end{array}$ & $\begin{array}{l}\text { Chichipo, Chiyol, Aguama, } \\
\text { Cazuela, Cocuixtle, } \\
\text { Jocuixtle, Cocuistle } \\
\text { (México). }\end{array}$ & $\begin{array}{l}\text { Infrutescencia nodular } 5 \text { a } 10 \text { cm de largo. } \\
\text { Bayas elipsoides, rosadas, de } 5.5 \text { a } 11 \text { cm } \\
\text { de largo, ferrugíneo-lepídotas. De } 50 \text { a } 100 \\
\text { frutos por racimo. }\end{array}$ & $\begin{array}{l}\text { Espejo-Serna et al. } \\
\text { (2005) }\end{array}$ \\
\hline Bromelia laciniosa Mart. & $\begin{array}{l}\text { Caroá, Macambira de } \\
\text { corda (Brasil). }\end{array}$ & $\begin{array}{l}\text { Infrutescencia con abundantes } \\
\text { exudaciones gomosas. Frutos cilíndricos } \\
\text { y alargados constituidos con numerosas } \\
\text { bayas anaranjadas, triloculares y } \\
\text { pluriseminados. }\end{array}$ & Buttazzoni et al. (1984) \\
\hline Bromelia serra Griseb. & Sin nombre común. & $\begin{array}{l}\text { Infrutescencia globosa de } 10-14 \mathrm{~cm} \text { de } \\
\text { largo por } 7-10 \mathrm{~cm} \text { de diámetro. Integrada } \\
\text { por bayas ovoides de } 4 \mathrm{~cm} \text { por } 2.5 \mathrm{~cm} \text { de } \\
\text { color amarillo limón. }\end{array}$ & Caffini et al. (1988) \\
\hline
\end{tabular}

Abreu et al., 2005a).

Moyano et al. (2012) reportaron que en frutos verdes de la especie B. karatas L. se encontraron mayores contenidos de proteína, minerales (excepto potasio y magnesio), carbohidratos y fibra, que en los frutos maduros (Cuadro 2). B. karatas $L$. cubre la ingesta recomendada de fósforo (1250 mg) (FDA, 2001) y es mayormente nutritiva si se consume en estado verde; sin embargo, debido a la cantidad de proteínas encontradas (13.33\%), las cuales son consideradas proteasas, el fruto verde se consume cocinado. B. anthicanta Berthol. es rica en azúcares (45\%), princi- palmente monosacáridos, pero también se ha detectado la presencia de lípidos (18\%), tales como el ácido palmítico (C 16:0), ácido oleico (C 18:1n 9c) y linoleico (C 18:2n 6c) (Santos et al., 2009).

Se ha evidenciado la presencia cualitativa de antioxidantes en B. pinguin L., tales como compuestos fenólicos (taninos y flavonoides), terpenos, saponinas y ácidos grasos, pero no se han cuantificado (Abreu et al., 2001). Los frutos maduros de B. karatas L. presentaron mayor contenido de fenoles totales que los frutos verdes (409.9 y $290.3 \mathrm{mg}$ $100 \mathrm{~g}^{-1}$, respectivamente) y se identificó cualitativamente 


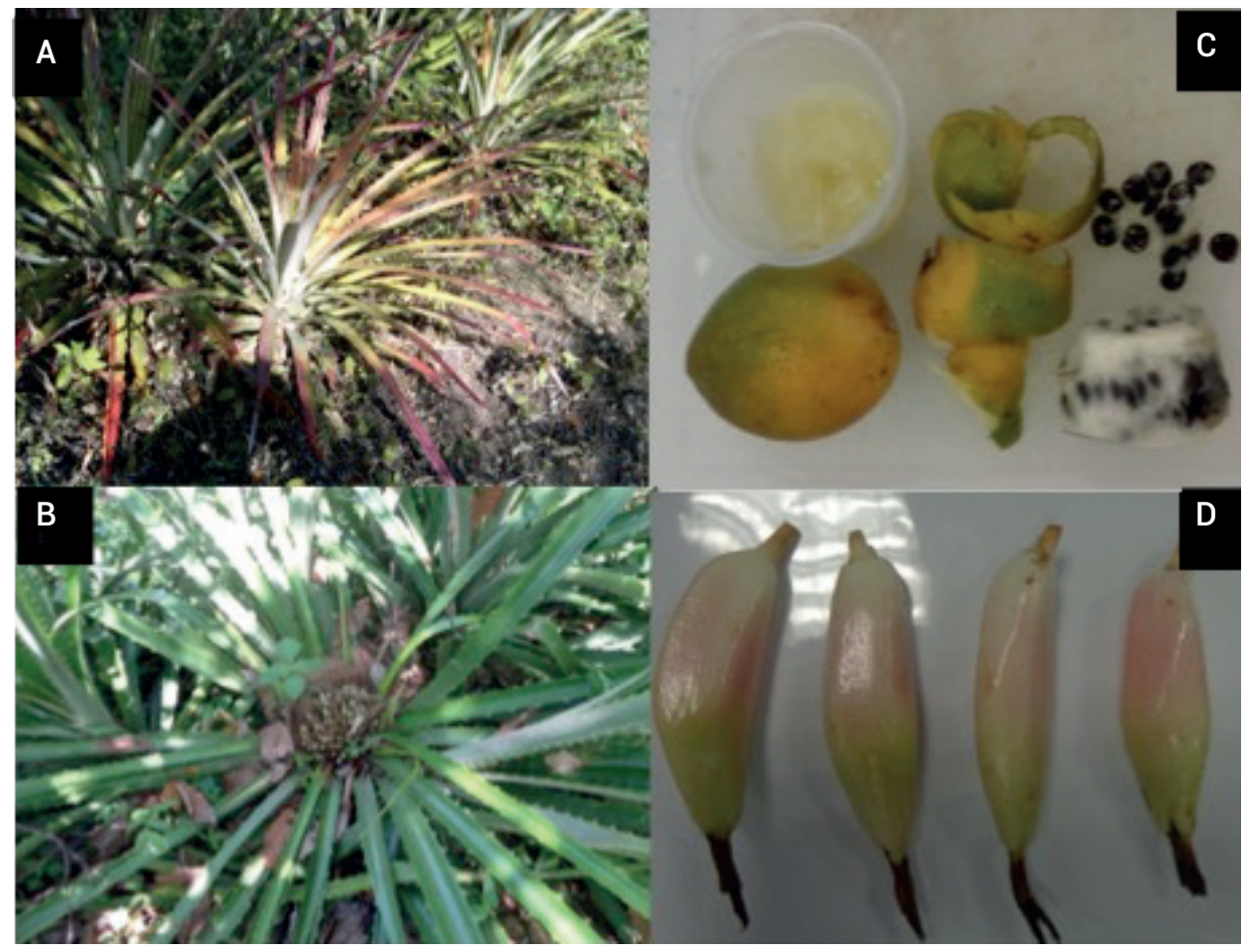

Figura 1. Fotografías de plantas (A y B) y frutos (C y D) de las especies Bromelia pinguin y Bromelia karatas cultivadas en Santiago Ixcuintla, Nayarit, México.

la presencia de flavonoides, terpenos y cumarinas tanto en la pulpa de frutos verdes como en frutos maduros; sin embargo, en frutos maduros se evidenció la presencia de taninos y fenilpropanoides (Moyano et al., 2012).

Por otra parte, Coelho et al. (2010) identificaron cualitativamente en pulpa de frutos de Bromelia balansae cuatro tipos de glucósido-flavonoles: kaempferol-3-0- $a-$ L-ramnopiranósido, kaempferol-3-O-a-L-ramnopiranosil 1-(1 $\rightarrow 6)-\beta-D-g l u c o p i r a n o ́ s i d o, \quad q u e r c e t i n a-3-0-a-L-$ ramnopiranosil-( $1 \rightarrow 6)-\beta$-D-glucopiranósido y kaempferol 3,7-di-O-a-L-ramnopiranósido.

Los frutos del género Bromelia tienen cantidades importantes de vitamina $\mathrm{C}$ y minerales tales como el calcio, fósforo y potasio; la detección cualitativa de compuestos bioactivos las hacen potencialmente funcionales, por lo que se debe cuantificar el contenido de estos compuestos para conferirles mayor valor agregado.

\section{USOS GENERALES Y ETNOBOTÁNICOS DE Bromelia}

Históricamente las plantas del género Bromelia, por las características morfológicas de las hojas con borde espinoso, son utilizadas para la construcción de cercas vivas. En la ganadería, estas especies son alimento y representan una fuente de agua en sitios muy secos; además, sus hojas presentan fibras de buena calidad para su producción a escala comercial; sin embargo, en la actualidad sólo son estudiadas desde el punto de vista ecológico, taxonómico y etnobotánico (Mondragón et al., 2011).

En el Cuadro 3 se describe el uso de once especies frutícolas de Bromelia reportadas para América Latina. Su uso tiene origen en las culturas prehispánicas desde hace miles de años; los Aztecas, Mayas, Incas, Quechuas, los Yanomami y otros pueblos las utilizaban como alimento, fibra, en ceremonias religiosas, como medicina y como plantas ornamentales, al igual que se siguen utilizando en la actualidad (Bennett, 2000; Hornung-Leoni, 2011a y 2011 b; Pierce 2000; Rondón, 2003).

En México los frutos de Bromelia se consumen como fruto fresco o se cocinan para inactivar las cisteína proteasas, enzimas responsables de provocar ardor en la boca después de su consumo en fresco (Hornung 2011a, b). En América Central y del Sur, las preparaciones de los frutos hervidos o infusiones se han utilizado para el tratamiento de la tos y otros trastornos del tracto respiratorio como bronquitis y asma (Argueta, 1994), escorbuto (Chan-Quijano et al., 2013), diabetes y trastornos del sistema urinario (Manetti et al., 2009). El jugo de los frutos ha sido utilizado como bebida refrescante, así como agente antihelmíntico (Abreu et al., 2001; Hornung-Leoni, 2011a). Chízmar (2009) reporta que el jugo de B. pinguin L. es empleado en Centroamérica contra los tricocéfalos y 
Cuadro 2 Caracterización nutrimental de frutos de Bromelias.

\begin{tabular}{|c|c|c|c|}
\hline $\begin{array}{l}\text { Composición proximal } \\
\text { (g } 100 \mathrm{~g}^{-1} \text { base seca) }\end{array}$ & $\begin{array}{l}\text { Bromelia pinguin } \mathrm{L}^{+} \\
\text {(Fruto fresco) }\end{array}$ & $\begin{array}{c}\text { Bromelia karatas L.+ } \\
\text { (Fruto fresco, maduro-verde) }\end{array}$ & $\begin{array}{l}\text { Bromelia anthiacanta } \\
\text { Berthol. }{ }^{9} \text { (Fruto seco) }\end{array}$ \\
\hline Humedad & 80.41 & $76.59-86.65$ & 27.3 \\
\hline Proteína & $7.20-13.87$ & $3.13-13.33$ & 8.30 \\
\hline Lípidos & 1.40 & $2.65-1.20$ & 18.20 \\
\hline Cenizas & $6.63-10.60$ & $4.22-12.00$ & 1.40 \\
\hline Fibra cruda & $3.35-3.41$ & $0.62-9.20$ & ND \\
\hline Carbohidratos & $5.31-15.14$ & $15.92-9.65$ & 44.80 \\
\hline Ácido fítico & 0.12 & ND & ND \\
\hline \multicolumn{4}{|l|}{ Minerales (mg $100 \mathrm{~g}^{-1} \mathrm{bs}$ ) } \\
\hline Calcio & $1200-1290$ & $290-1650$ & ND \\
\hline Cobalto & 1.20 & ND & ND \\
\hline Hierro & 1.70 & $0.056-0.092$ & ND \\
\hline Potasio & $903-2160$ & $670-630$ & ND \\
\hline Magnesio & $320-500$ & $470-390$ & ND \\
\hline Manganeso & 2.95 & ND & ND \\
\hline Sodio (Na) & 250 & 0.27 & ND \\
\hline Fósforo (P) & $56.65-160$ & $220-1140$ & ND \\
\hline Zinc (Zn) & 2.80 & ND & ND \\
\hline Vitamina C (mg $\left.100 \mathrm{~g}^{-1}\right)$ & 126.0 & $3.00-1.00$ & ND \\
\hline
\end{tabular}

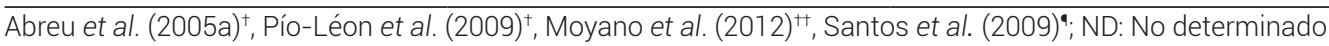

Cuadro 3. Usos tradicionales de plantas frutícolas del género Bromelia.

\begin{tabular}{|c|c|c|}
\hline Uso & Especie & País \\
\hline Comestible & $\begin{array}{l}\text { Bromelia alsodes H. St. John, Bromelia chrysantha } \\
\text { Jacq., Bromelia hemisphaerica L., Bromelia karatas } \\
\text { L., Bromelia pinguin L, Bromelia nidus-puellae } \\
\text { (André) André ex Mez. }\end{array}$ & $\begin{array}{l}\text { Argentina, Bolivia, Chile, Colombia, Costa Rica, Cuba, } \\
\text { Ecuador, El Salvador, Honduras, México, Nicaragua, } \\
\text { Panamá, Perú, Puerto Rico, Venezuela. }\end{array}$ \\
\hline Medicinal & $\begin{array}{l}\text { Bromelia balansae Mez., Bromelia hieronymi Mez., } \\
\text { Bromelia karatas L., Bromelia pinguin L., Bromelia } \\
\text { antiacantha Berthol., Bromelia fastuosa Lindl. }\end{array}$ & $\begin{array}{l}\text { Argentina, Bolivia, Brasil, Chile, Colombia, Cuba, } \\
\text { Ecuador, Honduras, México, Nicaragua, Perú, Puerto } \\
\text { Rico, Venezuela. }\end{array}$ \\
\hline Fibra textil & $\begin{array}{l}\text { Bromelia balansae Mez., Bromelia hieronymi Mez., } \\
\text { Bromelia pinguin L., Bromelia serra Griseb., Bromelia } \\
\text { laciniosa Mart. }\end{array}$ & $\begin{array}{l}\text { Brasil, Bolivia, Chile, Ecuador, México, Nicaragua, } \\
\text { Venezuela. }\end{array}$ \\
\hline Ceremonial & Bromelia chrysantha Jacq. & Bolivia, México, Perú, Venezuela. \\
\hline Cercos vivos & $\begin{array}{l}\text { Bromelia alsodes H. St. John, Bromelia karatas L., } \\
\text { Bromelia nidus-puellae (André) André ex Mez. }\end{array}$ & Colombia, Ecuador, México, Panamá, Venezuela. \\
\hline
\end{tabular}

Fuente: Hornung-Leoni (2011a; b). 
otros parásitos similares. Asimismo, se sabe sobre su uso como diurético, antirreumático y en forma de cataplasma, se emplea para dislocaciones y fracturas.

A pesar de la diversidad de aplicaciones etnobotánicas que tienen los frutos de Bromelia, en esta revisión se encontraron pocos estudios para comprobar la mayoría de esas aplicaciones. Aún no es clara la definición de los compuestos que podrían causar efectos medicinales al consumir los frutos; sin embargo, existe una constante mención de la acción terapéutica de sus proteasas y metabolitos secundarios, por lo que existe una amplia perspectiva de investigación científica que debe llevarse a cabo en esta área.

\section{PROTEASAS EXTRAÍDAS DE FRUTOS DE Bromelia}

Los frutos de Bromelia se consideran ricos en proteasas y se conoce sólo de manera general que éstas juegan un papel fisiológico importante para el desarrollo y movilización de proteínas germinales en respuesta a varios tipos de estrés medioambiental, en la defensa contra plagas y patógenos, muerte celular programada y senescencia de los mismos (Martínez et al., 2007). El tipo de proteasas identificadas en dichos frutos son cisteína proteasas, y aunque hasta hoy ninguna de ellas tiene una clasificación numérica de la EC (Enzyme Commision Numbers, por sus siglas en inglés) se conocen algunas características de proteasas extraídas y éstas se describen en el Cuadro 4.

\section{Bromelia karatas L. (Cocuixtle)}

En esta especie se identificó la proteasa karatasina, una proteasa sulfhidrilada o cisteína proteasa correspondiente a una glicoproteína con el $7 \%$ de carbohidratos, muy similar a la bromelina (EC 3.4.22.33); está constituida por un complejo de ocho formas moleculares múltiples cuyos puntos isoeléctricos ( $\mathrm{pl}$ ) se localizan en el intervalo de $\mathrm{pH}$ de 3.4 a 10.4; tiene un peso molecular de 23.8 kDa, es susceptible a la inhibición con agentes bloqueantes de grupo tiol, como el acetato fenilmercúrico, su actividad es inducida por cisteína y tiene una actividad específica total de 0.5 U mg-1 (Montes et al., 1990).

\section{Bromelia balansae Mez. (Caraguatá)}

Pardo et al. (2000; 2001) encontraron en esta especie la proteasa llamada balansaína, la cual tiene un pl de 5.4, pH óptimo de 8.8 a 9.2 y su peso molecular es de 23.2 kDa. La especie presenta una alta estabilidad térmica a $75^{\circ} \mathrm{C}$ con una pérdida mínima de su actividad proteolítica. La secuencia N-terminal mostró una homología muy alta (85$90 \%)$ con otras endopeptidasas conocidas de la familia Bromeliaceae como la piña (Annanas comosus L.).

\section{Bromelia pinguin L. (Guámara)}

Las proteasas de la especie purificadas parcialmente tienen características de cisteína proteasas; presentan un pH óptimo dentro del rango alcalino ( $\mathrm{pH} 7.2$ a 8.8); tienen una inhibición de la actividad proteolítica por sustancias que poseen grupos tiol, esta inhibición es normalmente revertida por la adición de cisteína; además, muestran una notable estabilidad térmica, así como una elevada estabilidad en altos valores de fuerza iónica (pl entre 4, 6 y 8, 1). El peso molecular aproximado de los cuatro componentes proteicos que integran el complejo enzimático es de 23 kDa (Abreu et al., 2005b y Abreu et al., 2008).

\section{Bromelia antiacantha Berthol. (Banano silvestre)}

Las proteasas de los frutos tienen una actividad proteolítica mayor al 80 \%, con dos óptimos de $\mathrm{pH} 5.0$ y 9.0. Tienen alta estabilidad térmica, ya que mantienen una actividad residual mayor de 90 \% después de calentar durante 60 min a $60^{\circ} \mathrm{C}$. La actividad de la enzima es inhibida completamente por el compuesto trans-epoxisuccinil-L-leucilamido-butano (E-64) y el ácido yodo acético, recuperando su actividad con la adición de cisteína o $\beta$-mercaptoetanol, lo que sugiere que pertenece al grupo de las cisteína proteasas y tiene su pl entre 7.6, 8.2 y 8.8 (Vallés et al., 2007).

\section{Bromelia hemisphaerica L. (Timbiriche)}

En esta especie se ha caracterizado la proteasa hemisfericina, con pl a un intervalo de 3.5 a 9.0, con formas aniónicas, catiónicas y neutras, todas con actividad proteolítica y esterolítica (León-Alcalá et al., 1989). Cortés-Vázquez et al. (2008) reportaron un peso molecular de 24 kDa, aunque su estructura completa no ha sido elucidada.

\section{Bromelia fastuosa Lindl. (Gravatá)}

De esta especie se han extraído cisteína proteasas de fruto inmaduro; se reportan proteasas con un peso molecular de 24-25 kDa, y al menos una proteasa denominada fastuosaina, posee alta actividad a pH 7.0. Su estructura posee 217 residuos de aminoácidos y su secuencia primaria mostró una alta homología con ananaína (EC 3.4.22.31) con $74 \%$, bromelina con 66 \% y papaína (EC 3.4.22.2) con $44 \%$ (Cabral et al., 2006).

\section{Bromelia hieronymi Mez. (Chaguar)}

Bruno et al. (2002) reportan que las proteasas de esta especie mostraron una actividad menor al $80 \%$ a un $\mathrm{pH}$ de 7.3 a 10.7, pero mostraron una gran estabilidad térmica conservando su actividad proteolítica residual de $80 \%$ después de calentar el extracto enzimático a $60{ }^{\circ} \mathrm{C}$ 
Cuadro 4. Características enzimáticas de proteasas aisladas de frutos de Bromelias.

\begin{tabular}{|c|c|c|c|c|c|c|}
\hline Proteasa & Especie & pH óptimo & $\begin{array}{l}\text { Temperatura } \\
\text { óptima }\left({ }^{\circ} \mathrm{C}\right)\end{array}$ & $\begin{array}{l}\text { Actividad } \\
\text { específica }\end{array}$ & $\begin{array}{l}\text { Peso molecular } \\
\qquad(\mathrm{kDa})\end{array}$ & Referencia \\
\hline Karatasina & $\begin{array}{l}\text { Bromelia plumieri } \\
\text { (E. Morren) L.B. Sm. }\end{array}$ & $3.4-10.4$ & $>40<60$ & $0.5 \mathrm{U} \mathrm{mg}^{-1}$ & 23.84 & Montes et al. (1990) \\
\hline Balansaína & $\begin{array}{l}\text { Bromelia balansae } \\
\text { Mez. }\end{array}$ & $8.8-9.2$ & $37-40$ & $35.4 \cup_{\mathrm{mg}^{-1}}$ & 23.20 & Pardo et al. (2001). \\
\hline Pinguinaína & Bromelia pinguin L. & $7.2-8.8$ & $45-60$ & $\begin{array}{l}3.2 \mathrm{U} \mathrm{mg}^{-1} \\
11 \mathrm{U} \mathrm{mL}^{-1}\end{array}$ & 23.0 & $\begin{array}{l}\text { Moreno-Hernández } \\
\text { et al. (2016); Abreu } \\
\text { et al. (2005b); Abreu } \\
\text { et al. (2008). }\end{array}$ \\
\hline Antiacanthaína & $\begin{array}{l}\text { Bromelia } \\
\text { anticantha Berthol. }\end{array}$ & $5.0-9.0$ & $42-63$ & $30.9 \cup \mathrm{mL}^{-1}$ & ND & $\begin{array}{l}\text { Vallés et al. (2007); } \\
\text { Macció et al. (2013). }\end{array}$ \\
\hline Hemisfericina & $\begin{array}{l}\text { Bromelia } \\
\text { hemisphaerica L. }\end{array}$ & $7.0-8.0$ & $35-40$ & $\begin{array}{c}890-980 \mathrm{U} \\
\mathrm{mg}^{-1}\end{array}$ & 24.0 & $\begin{array}{l}\text { Cortés-Vázquez et } \\
\text { al. (2008). }\end{array}$ \\
\hline Fastuosaina & $\begin{array}{l}\text { Bromelia fastuosa } \\
\text { Lindl. }\end{array}$ & 7.0 & $50-60$ & $1.3 \cup \mathrm{mg}^{-1}$ & $24-25$ & Cabral et al. (2006). \\
\hline $\begin{array}{l}\text { Hieronimaína I, } \\
\text { |I y III }\end{array}$ & $\begin{array}{l}\text { Bromelia hieronymi } \\
\text { Mez. }\end{array}$ & $7.5-9.0$ & 55 & $37.5 \mathrm{Ug} \mathrm{g}^{-1}$ & 24.06 & $\begin{array}{l}\text { Bruno et al. (2003); } \\
\text { Bruno et al. (2006); } \\
\text { Bruno et al. (2008). }\end{array}$ \\
\hline $\mathrm{SN}^{+}$ & $\begin{array}{l}\text { Bromelia serra } \\
\text { Griseb. }\end{array}$ & $6.0-7.8$ & 65 & ND & ND & Caffini et al. (1988). \\
\hline
\end{tabular}

$\mathrm{SN}^{+}=\sin$ nombre; $\mathrm{ND}^{\bullet}=$ no determinado.

por 30 min. Las bajas concentraciones de cloruro de sodio $(0.2 \mathrm{M})$ no afectaron su actividad caseinolítica, pero ésta disminuyó con el incremento de concentración salina en el medio de extracción (disminuye a 52 \% la actividad residual cuando la concentración de cloruro de sodio es de 2.5 M). Por cromatografía de intercambio catiónico se logró aislar la fracción principal, denominada hieronimaína I (pl > 9.3, peso molecular de 25 kDa). En el año 2010 se reportó el aislamiento de la hieronimaína II en la misma especie, con un peso molecular de $23.4 \mathrm{kDa}$, con una máxima actividad proteolítica de $90 \%$ a pH 7.5 y 9.0 sobre caseína. Su secuencia amino terminal fue comparada con 12 cisteína proteasas extraídas de plantas, mostrando un $70 \%$ de homología (Bruno et al., 2010).

\section{Bromelia serra Griseb}

Las proteasas de esta especie son las menos estudiadas. La información al respecto es prácticamente nula y se reporta solamente un estudió del año 1988, donde se menciona que un extracto crudo de proteasas tuvo su máximo de actividad caseinolítica a pH de 6.0 a 7.8 y una temperatura de $60^{\circ} \mathrm{C}$ (Caffini et al., 1988).

No existe una caracterización enzimática completa de todas las proteasas identificadas en Bromelia; sin embar- go, se puede inferir que son proteasas que tiene una alta actividad proteolítica en amplios rangos de $\mathrm{pH}$, algunas resistentes a temperaturas térmicas y de pesos moleculares similares. Se debe continuar con estudios sobre su caracterización y secuenciación enzimática para encontrar alternativas de uso.

\section{ACTIVIDAD BIOLÓGICA DE EXTRACTOS DE FRUTOS DE Bromelia}

La actividad farmacológica de cisteína proteasas vegetales ha sido probada contra algunos tratamientos terapéuticos, entre ellos trastornos digestivos, úlceras cutáneas y gástricas de diferentes orígenes, modulación inmunológica y trastornos tumorales (Salas et al., 2008). Otros investigadores han resaltado las propiedades medicinales y terapéuticas de las cisteína proteasas tales como: anti-edematosas, anti-inflamatorias, anti-trombóticas, contra bronquitis, asma y efectos fibrinolíticos (Guimarães-Ferreira et al., 2007; Maurer, 2001). En Estados Unidos de América (E.E. U.U.) y Europa la bromelina y otras proteasas (e.g. tripsina y quimiotripsina) son usadas como una alternativa o terapia complementaria a glucocorticoides, antirreumáticos no esteroideos e inmunomodulares; su baja toxicidad hace que su uso sea una herramienta útil en el tratamiento de la inflamación crónica (Brien et al., 
2004; Maurer, 2001). Esto sugiere que las proteasas obtenidas de las Bromelias mencionadas tienen potencial para ser utilizadas para el mismo fin.

Específicamente, las actividades biológicas reportadas para extractos de pulpa de frutos del género Bromelia se observan en el Cuadro 5. Los estudios de citotoxicidad encontrados revelan que los extractos acuoso, etanólico o metanólico obtenidos de pulpa de frutos de B. pinguin L., y $B$. anthiacanta Berthol., presentan una moderada o baja toxicidad evaluada en Artemia salina, concluyendo que los frutos pueden ser consumidos de manera segura (Abreu et al., 2001; Manetti et al., 2010; Santos et al., 2009).

Se reporta una buena actividad antihelmíntica, ya que usando una relación 10:90 (p/v) de extracto etanólico o agua y pulpa de fruto de $B$. pinguin $L$. se pudo observar una mayor actividad contra Lumbricus terrestres y Trichomonas vaginalis en comparación con la piperazina al $2 \%$ (Abreu et al., 2001).

La actividad antibacteriana también ha sido reportada para especies de Bromelia. Pío-León et al. (2009) y RuizRuiz et al. (2017) demostraron que los extractos etanólicos y acuosos obtenidos de pulpa de B. pinguin L. inhibieron el crecimiento de Staphylococcus aureus, Enterococcus faecalis, Salmonella typhi, Shigella flexneri, Shigella dysenteriae, Pseudomonas aeruginosa y Escherichia coli. Camacho-Hernández et al. (2002), por su parte, mencionan que el extracto etanólico de la pulpa del mismo fruto sólo inhibió especies microbianas de Trichophyton spp. y Paecillomyces variotii, pero no de Candida albicans. El extracto metanólico obtenido de la pulpa de B. balansae Mez. tuvo una inhibición de $90 \%$ de Mycobacterium tuberculosis (Coelho et al., 2010), mientras que los extractos metanólicos de frutos de $B$. antiacantha Berthol. presentaron buena actividad contra Pseudomonas aeruginosa y E. coli (Fabri y da Costa et al., 2012).

La acción antibacteriana se atribuye a la presencia de metabolitos secundarios como taninos, flavonoides, alcaloides, saponinas y a la presencia de las cisteína proteasas que podrían hidrolizar proteínas específicas de los microorganismos evaluados (Camacho-Hernández et al., 2002; Pío-León et al., 2009). Estos resultados comprueban que los frutos de B. pinguin L. y B. anthiacanta Berthol. pueden tener una acción importante en la prevención de infecciones estomacales y B. balansae Mez en trastornos respiratorios; aunque se requieren de mayores estudios para encontrar cantidad de pulpa, tiempos de extracción, solventes y dosis específicamente efectivas.

Otra actividad importante que se ha reportado en la especie de B. plumieri (E. Morren) L.B. Sm. es como hi- poglucemiante; sin embargo, ésto sólo se ha estudiado en las hojas y no en los frutos. Andrade-Cetto y MedinaHernández (2013) encontraron que un extracto acuoso o metanólico de hojas fue efectivo para disminuir la glucosa sanguínea en ratas diabéticas después de 120 min de tratamiento. Aunque los autores no explican el mecanismo de acción, mencionan que se identificó cualitativamente la presencia de flavonas y flavonoles en los extractos, por lo que atribuyeron la acción hipoglucemiante del extracto a estos compuestos, lo que coincide con el reporte de Torres-Piedra et al. (2010).

Proteasas liofilizadas obtenidas del fruto de B. hieronymi Mez. se estudiaron para conocer su efecto antiinflamatorio en las extremidades de ratas Wistar inducidas a edema inflamatorio con carragenina o serotonina. Se utilizaron dosis de cisteína proteasas de 45, 90 y $180 \mathrm{mg} \mathrm{kg}^{-1}$ de peso de las ratas y se comprobó el efecto de las proteasas en la inflamación incluyendo o no un inhibidor (E64) de las mismas, en la dosis administrada (Errasti et al., 2013). El proceso de formación del edema se lleva a cabo en dos fases, en la primera fase ocurre la liberación de histamina, serotonina y bradicina, que actúan como vasodilatadores y quimio-atrayentes de células inflamatorias; mientras que la segunda fase se conforma por el aumento de prostaglandinas (vasodilatador y aumento de permeabilidad vascular) inducido por la activación de la enzima prostaglandina-endoperóxido sintasa (EC 1.14.99.1) o también llamada COX-2, que continua con la infiltración de neutrófilos y su activación in situ (Errasti et al., 2013).

Errasti et al. (2013) mencionan que las cisteína protesas tuvieron efecto sobre la primera fase de la inflamación de las patas del animal, aunque el efecto fue muy limitado, considerando que fue por la cantidad de enzima usada, siendo la razón por la que no actúa al inicio de la inflamación. Los autores mencionan que el probable efecto antiinflamatorio se puede dar principalmente en la segunda fase, que suele aparecer entre 3 y 6 h después de la inyección de carragenina o serotonina. Se hipotetiza que el efecto antiinflamatorio tal vez es debido a la inhibición de la producción de prostaglandinas e inhibición de radicales de óxido nítrico (ambos vasodilatadores). Por lo tanto, no hubo permeabilidad vascular o ésta disminuyó y con ello se redujo o inhibió la infiltración de neutrófilos y por consecuencia su activación, disminuyendo la inflamación (Gaspani et al., 2002; Salvemini et al., 1996).

Errasti et al. (2013) concluyeron que en todos los modelos de inflamación evaluados en ratas existió una respuesta significativa en la disminución de la inflamación al suministrar una dosis de $180 \mathrm{mg} \mathrm{kg}^{-1}$ de proteasas liofilizadas, atribuyendo una respuesta directa a la actividad proteolítica de estas enzimas. 
Cuadro 5. Actividades biológicas de extractos obtenidos de frutos de Bromelias.

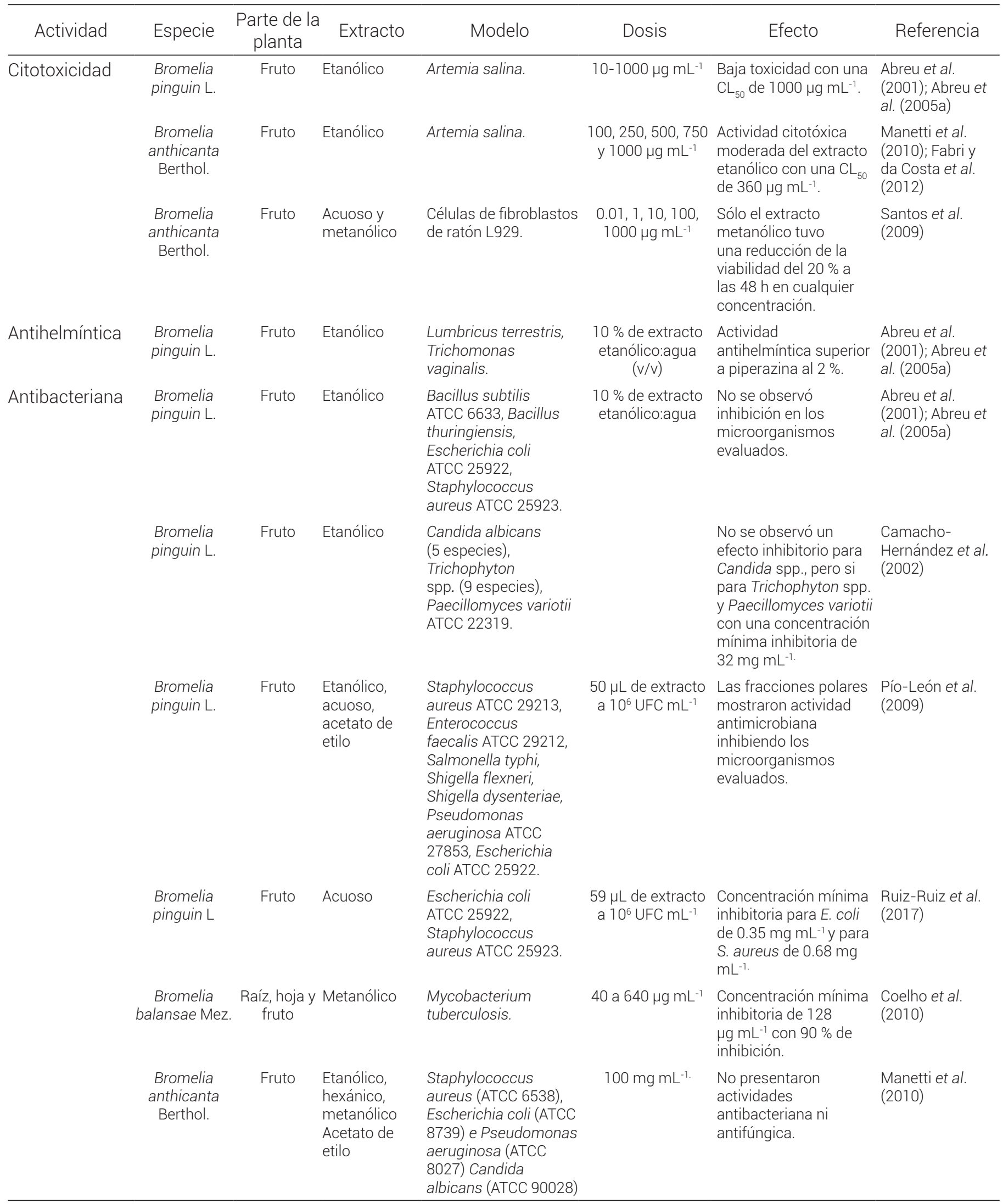


Cuadro 5. Continuación.

\begin{tabular}{|c|c|c|c|c|c|c|c|}
\hline Actividad & Especie & $\begin{array}{c}\text { Parte de la } \\
\text { planta }\end{array}$ & Extracto & Modelo & Dosis & Efecto & Referencia \\
\hline & $\begin{array}{l}\text { Bromelia } \\
\text { anthiacanta } \\
\text { Berthol. }\end{array}$ & Fruto & Metanólico & $\begin{array}{l}\text { Staphylococcus } \\
\text { aureus (ATCC 6538), } \\
\text { Pseudomonas } \\
\text { aeruginosa (ATCC } \\
\text { 15442), Escherichia } \\
\text { coli (ATCC 10536), } \\
\text { Shigella dysenteriae } \\
\text { (ATCC 13313), } \\
\text { Salmonella enterica } \\
\text { sorovar typhimurium } \\
\text { (ATCC 13311) e } \\
\text { Enterobacter cloacae } \\
\text { (ATCC 10699). }\end{array}$ & $\begin{array}{l}50 \mu \mathrm{L} \text { de extracto } \\
\text { a concentración } \\
\text { de } 5 \mathrm{mg} \mathrm{mL}^{-1} \text {. }\end{array}$ & $\begin{array}{l}\text { Acción inhibitoria solo } \\
\text { en Pseudomonas } \\
\text { aeruginosa y } \\
\text { Escherichia coli. }\end{array}$ & $\begin{array}{l}\text { Fabri y da Costa } \\
\text { et al. (2012) }\end{array}$ \\
\hline Hipoglucémico & $\begin{array}{l}\text { Bromelia } \\
\text { plumieri (E. } \\
\text { Morren). L.B. } \\
\text { Sm. }\end{array}$ & Hoja & $\begin{array}{l}\text { Acuoso y } \\
\text { etanólico }\end{array}$ & $\begin{array}{l}\text { Ratas diabéticas } \\
\text { inducidas con } \\
\text { estreptozotocina- } \\
\text { nicotinamida. }\end{array}$ & $\begin{array}{l}35 \text { y } 350 \text { mg kg-1 } \\
\text { acuoso, } 30 \text { y } 350 \\
\text { mg kg etanólico. }\end{array}$ & $\begin{array}{l}\text { Hipoglucemia } \\
\text { después de } 120 \text { min } \\
\text { de tratamiento, en } \\
\text { cualquiera de los dos } \\
\text { extractos. }\end{array}$ & $\begin{array}{l}\text { Andrade-Cetto } \\
\text { y Medina- } \\
\text { Hernández } \\
\text { (2013) }\end{array}$ \\
\hline Antiinflamatoria & $\begin{array}{l}\text { Bromelia } \\
\text { hieronymi Mez. }\end{array}$ & Fruto & $\begin{array}{l}\text { Proteasas } \\
\text { liofilizada }\end{array}$ & $\begin{array}{l}\text { Ratas Wistar albino } \\
\text { inducidas a edema } \\
\text { inflamatorio con } \\
\text { carragenina. }\end{array}$ & $\begin{array}{l}45,90, \text { y } 180 \text { mg } \\
k g^{-1} \text { de proteasa } \\
\text { por kg de peso. }\end{array}$ & $\begin{array}{l}\text { Máxima actividad } \\
\text { antiinflamatoria a las } 5 \\
\text { h, } 78 \text { \% de disminución } \\
\text { de la inflamación con } \\
180 \mathrm{mg} \mathrm{kg}^{-1} \text {. }\end{array}$ & $\begin{array}{l}\text { Errasti et al. } \\
\text { (2013) }\end{array}$ \\
\hline Antitumoral & $\begin{array}{c}\text { Bromelia } \\
\text { fastuosa Lindl. }\end{array}$ & Fruto & Fastuosaina & $\begin{array}{l}\text { Ratones C57Bl/6 con } \\
\text { metástasis tumoral } \\
\text { y células B16F10- } \\
\text { Nex2 de melanoma } \\
\text { murino. }\end{array}$ & $\begin{array}{l}\text { In vivo } 60 \mu \mathrm{g} \text { por } \\
\text { animal, in vitro } 5 \mathrm{y} \\
10 \mu \mathrm{g} \mathrm{mL}\end{array}$ & $\begin{array}{l}\text { Efecto antitumoral. } \\
\text { Invoca el agotamiento } \\
\text { proteolítico y pérdida } \\
\text { de adherencia de las } \\
\text { células del tumor. }\end{array}$ & $\begin{array}{l}\text { Guimarães- } \\
\text { Ferreira et al. } \\
\quad(2007)\end{array}$ \\
\hline
\end{tabular}

$\mathrm{CL}_{50}$ : concentración letal media; UFC: Unidades formadoras de colonias.

Guimarães-Ferreira et al. (2007) estudiaron el efecto antitumoral in vivo (Ratones C57BI/6 con metástasis tumoral) e in vitro (células B16F10-Nex2 de melanoma murino) de la fastuosaina, cisteína proteasa obtenida de frutos de B. fastuosa Lindl. Los autores concluyeron que la fastuosaina tiene efecto antitumoral en concentraciones in vivo de $60 \mu \mathrm{g} \mathrm{mL}^{-1}$ e in vitro de 5 y $10 \mu \mathrm{g} \mathrm{mL}^{-1}$.

Las células tumorales tratadas con fastuosaina mostraron pocos nódulos formados, con una reducción en la expresión de la CD44, glicoproteína encargada de la adhesión celular, por lo que es un componente importante para la migración de células tumorales. Se presentó una pérdida de extensión celular proangiogénico endotelial y un aumento de anticuerpos citotóxicos al tumor, elevados por la fastuosaina, y se formaron grupos pequeños de células unidas en suspensión. Además de reducir la expresión de CD44, la fastuosaina, en un modelo de colonización de melanoma de pulmón de murino B16F10-Nex2, inhibió la colonización en pulmón, demostrando que esta enzima tiene mayor actividad sobre células tumorales que sobre células normales; por lo tanto, las propiedades de la fastuosaina se deben en principio al efecto de la enzima directamente sobre células tumorales tanto in vivo como in vitro, así como también a un efecto de inmunización, que incrementa la cantidad de anticuerpos y un probable aumento de la citotoxicidad, que promueve la eliminación de células tumorales.

La actividad catalítica de las cisteína proteasas depende de la reactividad del grupo tiol del residuo de cisteína del centro activo, el cual rompe enlaces peptídicos de otras proteínas (Barret et al., 2013). Las cisteína proteasas se absorben bien en el intestino delgado después de ser administradas vía oral y no tienen efectos secundarios importantes, incluso después de uso prolongado; por tanto, se sugiere que las cisteína proteasas pueden ser utilizadas como un eficaz suplemento alimenticio para prevenir enfermedades (Pavan et al., 2012; Salas et al., 2008).

Por lo tanto, las cisteína proteasas de Bromelia presentan actividades biológicas importantes que pueden ser usadas en la medicina alternativa. A largo plazo, las cisteína proteasas se perfilan como candidatas prometedoras para el desarrollo de terapias enzimáticas por vía oral, pero se requiere de mayores investigaciones. 


\section{ESTUDIOS TECNOLÓGICOS DE PROTEASAS DE FRUTOS DE Bromelia}

El uso de enzimas se ha convertido en una parte indispensable de los procesos utilizados por la industria de alimentos para producir una amplia y diversificada gama de productos para el consumo humano y animal (Shahidi y Janak Kamil, 2001). Hasta ahora las dos proteasas vegetales comerciales más usadas a nivel industrial son la papaína y la bromelina, para la producción de cerveza, panificación, tenderización de carnes y obtención de hidrolizados proteicos (Feijo-Siota y Villa, 2011; Moutim et al., 1999).

Las proteasas identificadas y purificadas de frutos de Bromelia representan una alternativa atractiva al empleo de la papaína o la bromelina en la industria alimentaria, debido a que se ha demostrado que pueden tener estabilidad a temperaturas elevadas y actúan en un mayor rango de pH (Montes et al., 1990); entre ellas se encuentran las mencionadas en el Cuadro 4.

Existen estudios científicos y tecnológicos realizados sobre el uso de proteasas de frutos del género Bromelia. Bruno et al. (2010) evaluaron la elaboración de queso con hieronimaína. Dichos autores encontraron que la hieronimaína fue capaz de coagular la leche; la fracción de k-caseína, directamente implicada en la formación de la coagulación comenzó a degradarse después de 10 min de reacción, mientras que la degradación de las otras fracciones de caseína avanzó lentamente, lo que garantizó la producción de una cuajada firme, sin evidencia de hidrólisis extensiva, condición necesaria para la elaboración de quesos. En la evaluación sensorial, los panelistas aceptaron los quesos que se fabricaron tanto con quimosina como con hieronimaína. Los autores concluyeron que esta preparación enzimática podría ser apropiada para la elaboración de queso como alternativa al combinarse con cuajo de ternera, pero es necesario realizar investigaciones adicionales sobre el rendimiento del queso, los efectos sobre el envejecimiento y la estabilidad de la preparación enzimática durante el almacenamiento; sin embargo, esas proteasas vegetales no se producen de manera comercial, ya que los frutos son cosechados de plantas silvestres, por lo que hasta hoy no podrían sustituir a la quimosina.

Por su parte, García y Penna (2010) estudiaron la combinación de quimosina y fastuosaina con diferentes actividades enzimáticas en la elaboración de queso bajo en grasa. La respuesta de hidrólisis durante la elaboración de los quesos dependió de la actividad enzimática de la fastuosaina, entre mayor actividad menor fue la firmeza de los quesos. Los autores concluyeron que el uso de la fastuosaina extraída del fruto verde de $B$. fastuosa podría ser una interesante alternativa para la mejora de la calidad de que- sos, ya que se mejoró la calidad de este producto bajo en grasa, no afectó la derretibilidad, ni produjo sabor amargo, una característica común en quesos bajos en grasa.

Otros estudios tecnológicos importantes con el uso de enzimas vegetales son los hidrolizados proteicos. En las últimas décadas los hidrolizados de proteínas han sido ampliamente estudiados debido a que se descubrió que en ellos se tenía la presencia de péptidos bioactivos (Harnedy y FitzGerald, 2012).

Los péptidos bioactivos encontrados en los hidrolizados son fragmentos específicos (2 a 20 residuos de aminoácidos) de proteínas que además de actuar como fuentes de nitrógeno y aminoácidos, tienen numerosas funciones fisiológicas en el organismo humano. Entre las actividades biológicas reportadas se incluyen como inmunomoduladores, antimicrobianos, antitrombóticos, antihipertensivos, antioxidantes, entre otros, debido a que los pequeños péptidos se absorben más rápidamente en el intestino (Cheung y Li-Chan, 2014; Harnedy y FitzGerald, 2012; Spellman et al., 2009). El uso de proteasas de frutos de Bromelia para obtener hidrolizados proteicos son casi nulos, por lo que en esta revisión se mencionan las únicas investigaciones reportadas.

Briones-Martínez et al. (1994) estudiaron el uso de la hemisfericina, proteasa obtenida de B. hemisphaerica L. en la solubilización de proteínas de pescado. Los autores demostraron la eficiencia de esta proteasa en la producción de hidrolizados de buena calidad nutricional, con un balance proporcionado de aminoácidos esenciales. También se reportó que estas proteasas hidrolizan eficazmente las proteínas adjuntas de la malta y son capaces de mejorar propiedades funcionales de proteínas vegetales de interés alimentario.

Bruno et al. (2010) evaluaron la capacidad de hidrólisis de hieronimaínas, utilizando como sustrato caseína y proteínas de suero láctico. Para evaluar la capacidad de hidrólisis se identificó la presencia o ausencia de las fracciones de caseína por análisis electroforético después de la proteólisis. Los autores reportaron que estas enzimas fueron capaces de hidrolizar la caseína y la proteína del suero de bovino debido a que corroboraron la presencia de las fracciones de caseína ( $a_{\mathrm{s} 1}$-caseína, $\mathrm{a}_{\mathrm{s} 2}$-caseína, bcaseína y k-caseína) en los hidrolizados, por lo que estas enzimas también se pueden utilizar para la obtención de hidrolizados ricos en péptidos con potencial biológico.

El estudio más recientemente reportado sobre el uso de proteasas para la obtención de hidrolizados ricos en péptidos bioactivos es con la enzima balansaína $R$, contenida en el extracto proteolítico obtenido de frutos maduros de 
B. balansae Mez. Se encontró que la balansaína R hidroliza las proteínas de suero de leche bovina comercial (WPC 80) degradando la $\beta$-lactoglobulina y a-lactoalbúmina en 80 y $15 \%$, respectivamente, después de 120 min. Los péptidos obtenidos tuvieron tamaños de 5-15 kDa y mostraron actividad antioxidante mayor que la leche sin hidrolizar (Prospitti et al., 2015).

\section{CONCLUSIONES}

Los estudios sobre extractos de frutos del género Bromelia demuestran que éstos tienen características nutricionales importantes, ya que son fuente de vitamina $\mathrm{C}$ y algunos minerales como el calcio, potasio y fósforo. Los extractos presentan actividad antibacteriana, antihelmíntica, hipoglucemiante, antiinflamatoria y antitumoral, por lo que pueden aprovecharse en la industria farmacéutica. Las especies estudiadas en Bromelia también representan una alternativa en la industria de alimentos. El número de proteasas de origen vegetal que se emplean industrialmente es todavía muy pequeño, pero está creciendo poco a poco debido a la abundancia relativa en algunas plantas y a sus atractivas características enzimáticas. Esto ha conducido a la selección de proteasas de diferentes especies de plantas silvestres para su aislamiento y caracterización con el fin de evaluar su potencial biotecnológico en el proceso de alimentos. Las investigaciones deben continuar en el futuro para aportar evidencias que esclarezcan con mayor certeza el efecto del consumo de frutos de Bromelia en la salud.

\section{BIBLIOGRAFÍA}

Abreu P. J., M. Miranda M., G. Toledo C. y 0. Castillo G. (2001) Actividad farmacológica preliminar del fruto de Bromelia pinguin L. (piña de ratón). Revista Cubana de Farmacia 35:56-60

Abreu P. J., D. M. González M., A. Meneses, M. E. de la Cruz, F. Banze, M. Miranda M. y 0. Ros L. (2005a) Determinación de parámetros farmacognósticos y bromatológicos y evaluación de la actividad antiparasitaria de una preparación obtenida del fruto de Bromelia pinguin $\mathrm{L}$. que crece en Cuba. Acta Farmacéutica Bonaerense 24:377-382

Abreu P. J., W. D. Obregón, C. L. Natalucci and N. O. Caffini (2005b) Reinvestigation of the proteolytically active components of Bromelia pinguin fruit. Fitoterapia 76:540-548.

Abreu P. J., W. D. Obregón, S. A. Trejo and N. O. Caffini (2008) Purification and characterization of four new cysteine endopeptidases from fruits of Bromelia pinguin L. grown in Cuba. The Protein Journal 27:88-96.

Andrade-Cetto A. and A. E. Medina-Hernández (2013) Hypoglycemic effect of Bromelia plumieri (E. Morren) L.B. Sm., leaves in STZ-NA-induced diabetic rats. Frontiers in Pharmacology 4. doi: 10.3389/ fphar.2013.00036.

Argueta V. A., L. M. Cano A. y M. E. Rodarte (1994) Atlas de las Plantas de la Medicina Tradicional Mexicana. Tomo II. Instituto Nacional Indigenista, Mexico, D.F. 559 p.

Barret A. J., N. D. Rawlings and J. F. Woessner (2013) Handbook of Proteolytic Enzymes. Academic Press. London, UK. 1743 p.

Bennett B. (2000) Ethnobotany of Bromeliaceae. In: Bromeliaceae: Profile of an Adaptive Radiation. D. H. Benzing, B. Bennet, G. Brown, M. Dimmitt, H. Luther, L. Ramírez, R. Terry and W. Till (eds.). Cambridge University Press. Cambridge, UK. pp: 587-608.

Brien S., G. Lewith, A. Walker, S. M. Hicks and D. Middleton (2004) Brome- lain as a treatment for osteoarthritis: a review of clinical studies. Evidence-Based Complementary and Alternative Medicine $1: 251-257$.

Briones-Martínez R., M. C. Oliver, M. T. Cruz y M. I. Cortés-Vázquez (1994) Preparaciones enzimáticas de interés industrial con proteinasas de plantas mexicanas. Revista Latinoamericana Información Tecnológica 5:29-38.

Bruno M. A., M. F. Pardo, N. O. Caffini and L. M. I. López (2002) Purification of a new endopeptidase isolated from fruits of Bromelia hieronymi Mez. (Bromeliaceae). Acta Farmaceutica Bonaerense 21:51-56.

Bruno M. A., M. F. Pardo, N. O. Caffini and L. M. I. López (2003) Hieronymain I, a new cysteine peptidase isolated from unripe fruits of Bromelia hieronymi Mez. (Bromeliaceae). Journal of Protein Chemistry 22:127-134

Bruno M. A., S. A. Trejo, X. F. Avilés, N. O. Caffini and L. M. I. López (2006) Isolation and characterization of hieronymain II, another peptidase isolated from fruits of Bromelia hieronymi Mez. (Bromeliaceae). The Protein Journal 25:224-231.

Bruno M. A., S. A. Trejo, N. O. Caffini and L. M. I. López (2008) Purification and characterization of hieronymain III. Comparison with other proteases previously isolated from Bromelia hieronymi Mez. The Protein Journal 27:426-433.

Bruno M. A., C. M. Lazza, M. E. Errasti, L. M. I. López, N. O. Caffini and M. F. Pardo (2010) Milk clotting and proteolytic activity of an enzyme preparation from Bromelia hieronymi fruits. LWT-Food Science and Technology 43:695-701.

Buttazzoni C. M. S., N. O. Caffini, C. L. Natalucci and N. S. Priolo L. (1984) Proteasas de Bromeliaceae. I. Estudio preliminar de la fracción proteolíticamente activa presente en frutos de Bromelia laciniosa Mart. Acta Farmacéutica Bonaerense 3:33-38.

Cabral H., A. M. Leopoldino, E. H. Tajara, L. J. Greene, V. M. Faça, R. P. Mateus, C. R. Ceron, W. A de Souza Judice, L. Juliano and G. O. Bonilla-Rodriguez (2006) Preliminary functional characterization, cloning and primary sequence of fastuosain, a cysteine peptidase isolated from fruits of Bromelia fastuosa. Protein and Peptide Letters 13:83-89.

Caffini N. O., C. L. Natalucci, N. S. Priolo and M. S. Buttazzoni (1988) Proteasas de Bromeliaceae. IV. Aislamiento de una fitoproteasa sulfhídrica presente en frutos de Bromelia serra Griseb. Acta Farmaceutica Bonaerense 7:9-14

Camacho-Hernández I. L., J. A. Chávez-Velázquez, M. J. Uribe-Beltrán, A. Ríos-Morgan and F. Delgado-Vargas (2002) Antifungal activity of fruit pulp extract from Bromelia pinguin. Fitoterapia 73:411-413.

Chan-Quijano J. G., M. K. Pat-Canché y J. Saragos-Méndez (2013) Conocimiento etnobotánico de las plantas utilizadas en Chancah Veracruz, Quintana Roo, México. Teoría y Praxis 14:9-24.

Cheung I. W. Y. and E. C. Y. Li-Chan (2014) Application of taste sensing system for characterisation of enzymatic hydrolysates from shrimp processing by-products. Food Chemistry 145:10761085.

Chízmar F. C. (2009) Plantas Comestibles de Centroamérica. Instituto Nacional de Biodiversidad. Editorial INBio. Santo Domingo de Heredia, Costa Rica. 358 p.

Coelho R. G., N. K. Honda, M. C. Vieira, R. L. Brum, F. R. Pavan, C. Q. F. Leite and C. A. L. Cardoso (2010) Chemical composition and antioxidant and antimycobacterial activities of Bromelia balansae (Bromeliaceae). Journal of Medicinal Food 13:1277-1280.

Cortés-Vázquez M. I., J. L. Muñoz-Sánchez and R. Briones-Martínez (2008) Substrate specificity of a cationic peptidase from Bromelia hemisphaerica L. Natural Product Communications 3:351-355.

Díaz P. W. A. and F. Delascio-Chitty (2007) Catálogo de plantas vasculares de Ciudad Bolívar y sus alrededores, estado Bolívar, Venezuela. Acta Botánica Venezuelica 30:99-161.

Errasti M. E., N. O. Caffini, L. E. Pelzer and A. E. Rotelli (2013) Anti-inflammatory activity of Bromelia hieronymi: comparison with bromelain. Planta Medica 79:207-213.

Espejo-Serna A., A. R. López-Ferrari, I. Ramírez-Morillo, B. K. Holst, H. E. Luther and W. Till (2004) Checklist of Mexican Bromeliaceae with notes on species distribution and levels of endemism. Selbyana 25:33-86

Espejo-Serna A., A. R. López-Ferrari and I. Ramírez-Morillo (2005) Flora de Veracruz. Bromeliaceae. Fascículo 136. Instituto de Ecología A. C. Xalapa, Veracruz. 307 p. 
Fabri R. L. e J. A. B. M. da Costa (2012) Perfil farmacognóstico e avaliação das atividades citotóxica e antibacteriana de Bromelia antiacantha Bertol. Revista Eletrônica de Farmácia 9:37-48.

FDA, Food and Drug Administration (2001) CFR - Code of Federal Regulations, Title 21. https://www.gpo.gov/fdsys/pkg/CFR-2016-title21-vol2/pdf/CFR-2016-title21-vol2-sec101-9.pdf (Junio 2017).

Feijoo-Siota L. and T. G. Villa (2011) Native and biotechnologically engineered plant proteases with industrial applications. Food and Bioprocess Technology 4:1066-1088.

García G. A. C. e A. L. B. Penna (2010) Queijo prato com teor reduzido de gordura adicionado de enzima proteolítica: características físicas e sensoriais. Revista do Instituto Adolfo Lutz 69:346-357.

Gaspani L., E. Limiroli, P. Ferrario and M. Bianchi (2002) In vivo and in vitro effects of bromelain on $\mathrm{PGE}_{2}$ and $\mathrm{SP}$ concentrations in the inflammatory exudate in rats. Pharmacology 65:83-86

González-Salvatierra C., J. L. Andrade, R. Orellana, L. M. Peña-Rodríguez y C. Reyes-García (2013) Microambiente lumínico y morfología y fisiología foliar de Bromelia karatas (Bromeliaceae) en una selva baja caducifolia de Yucatán, México. Botanical Sciences 91:75-84.

Guimarães-Ferreira C. A., E. G. Rodrigues, R. A. Mortara, H. Cabral, F. A. Serrano, R. Ribeiro-dos-Santos and L. R. Travassos (2007) Antitumor effects in vitro and in vivo and mechanisms of protection against melanoma B16F10-Nex2 cells by fastuosain, a cysteine proteinase from Bromelia fastuosa. Neoplasia 9:723-733.

Harnedy P. A. and R. J. FitzGerald (2012) Bioactive peptides from marine processing waste and shellfish: a review. Journal of Functional Foods 4:6-24

Hornung-Leoni C. T. (2011a) Bromeliads: traditional plant food in Latin America since prehispanic times. Polibotánica 32:219-229.

Hornung-Leoni C. T. (2011b) Avances sobre usos etnobotánicos de las Bromeliaceae en Latinoamérica. Boletín Latinoamericano y del Caribe de Plantas Medicinales y Aromáticas 10:297-314.

Ledesma S. J. A., A. Chávez V., F. Pérez-Gil, R. E. Mendoza M. y C. Calvo C. (2010) Composición de Alimentos Miriam Muñoz de Chávez. Valor Nutritivo de los Alimentos de Mayor Consumo. $2^{\text {a }}$ edición. Mc Graw Hill Interaméricana, México, D.F. 365 p.

León-Alcalá F., L. A. Rivas-Rueda, V. M. T. Cruz, M. Castañeda-Agulló and L. M. Del Castillo (1989) Enzymes of Mexican plants XVI. Separation of multiple molecular forms of hemisphaericin and palmerin. Revista Latinoamericana de Química 20:133-136.

Macció L., D. Vallés and A. M. Cantera (2013) Proteolytic enzymes from Bromelia antiacantha as tools for controlled tissue hydrolysis in entomology. SpringerPlus 2:307. https://doi.org/10.1186/21931801-2-307.

Manetti L. M., R. H. Delaporte e A. Laverde Jr. (2009) Metabólitos secundários da família Bromeliaceae. Química Nova 32:1885-1897.

Manetti L. M., A. F. Turra, O. S. Takemura, T. I. E. Svidzinski e A. Laverde Jr. (2010) Avaliação das atividades antimicrobiana, citotóxica, moluscicida e antioxidante de Bromelia antiacantha Bertol. (Bromeliaceae). Revista Brasileira de Plantas Medicinais 12:406413.

Martinelli, G., C. M. Vieira, M. Gonzalez, P. Leitman, A. Piratininga, A. F. da Costa and R. C. Forzza (2008) Bromeliaceae da Mata Atlântica brasileira: lista de espécies, distribuição e conservação. Rodriguésia 59:209-258.

Martínez D. E., C. G. Bartoli, V. Grbic and J. J. Guiamet (2007) Vacuolar cysteine proteases of wheat (Triticum aestivum L.) are common to leaf senescence induced by different factors. Journal of Experimental Botany 58:1099-1107.

Maurer H. R. (2001) Bromelain: biochemistry, pharmacology and medical use. CMLS Cellular and Molecular Life Sciences 58:12341245.

Mondragón C. D. M., I. M. Ramírez M., M. M. Flores C. y J. G. García F. (2011) La Familia Bromeliaceae en México. Universidad Autónoma Chapingo. Chapingo, Texcoco, México. 100 p.

Monteiro, R. F., A. Mantovani and R. C. Forzza (2015) Morphological phylogenetic analysis of two early-diverging genera of Bromelioideae (Bromeliaceae). Rodriguésia 66:505-521.

Montes C., M. Amador, D. Cuevas and F. Cordoba (1990) Subunit structure of karatasin, the proteinase isolated from Bromelia plumieri (karatas). Agricultural and Biological Chemistry 54:17-24.

Moreno-Hernández, J. M., X. D. Hernández-Mancillas, E. L. Coss N., M. A. Mazorra-Manzano, I. Osuna-Ruiz, V. A. Rodríguez-Tirado and J. A. Salazar-Leyva (2017) Partial characterization of the proteolytic properties of an enzymatic extract from "Aguama" Bromelia pinguin L. fruit grown in Mexico. Applied Biochemistry and Biotechnology 182:181-196.

Moutim V., L. G. Silva, M. T. P. Lopes, G. W. Fernandes and C. E. Salas (1999) Spontaneous processing of peptides during coagulation of latex from Carica papaya. Plant Science 142:115-121.

Moyano D. D., M. Osorio R., E. Murillo P., W. Murillo A., J. Solanilla D., J. Méndez A. y J. Aristizabal S. (2012) Evaluación de parámetros bromatológicos, fitoquímicos y funcionalidad antioxidante de frutos de Bromelia karatas (Bromeliaceae). Vitae 19:S439-S441

Pardo M. F., L. M. I. López, F. Canals, F. X. Avilés, C. L. Natalucci and N. 0 Caffini (2000) Purification of balansain I, an endopeptidase from unripe fruits of Bromelia balansae Mez. (Bromeliaceae). Journal of Agricultural and Food Chemistry 48:3795-3800.

Pardo M. F., L. M. I. López, N. O. Caffini and C. L. Natalucci (2001) Properties of a milk clotting protease isolated from fruits of Bromelia balansae Mez. Biological Chemistry 382:871-874.

Pavan R., S. Jain, Shraddha and A. Kumar (2012) Properties and therapeutic application of bromelain: a review. Biotechnology Research International 2012. doi:10.1155/2012/976203.

Pierce S. (2000) The use of Tillandsia species in ritual adornment in Qosqo, Peru. Journal of the Bromeliad Society 50:195-201.

Pío-León J. F., G. López-Angulo, O. Paredes-López, M. J. Uribe-Beltrán, S. P. Díaz-Camacho and F. Delgado-Vargas (2009) Physicochemical, nutritional and antibacterial characteristics of the fruit of Bromelia pinguin L. Plant Foods for Human Nutrition 64:181-187.

Prospitti A., L. N. Cancelarich, J. Perrando, C. L. Natalucci and M. F. Pardo (2015) Balansain R, a new proteolytic preparation for the production of antioxidant peptides from bovine whey. Latin American Journal of Pharmacy 34:1387-1395.

Rondón R. J. A. (2003) Temas etnobotánicos. Vocablos Piaroa de algunas artesanías de origen forestal del estado Amazonas, Venezuela. Revista Forestal Latinoamericana 34:71-86.

Ruiz-Ruiz J. J., J. Ramón-Sierra, C. Arias-Argaez, D. Magaña-Ortiz and E. Ortiz-Vázquez (2017) Antibacterial activity of proteins extracted from the pulp of wild edible fruit of Bromelia pinguin L. International Journal of Food Properties 20:220-230

Salas C. E., M. T. R. Gomes, M. Hernandez and M. T. P. Lopes (2008) Plant cysteine proteinases: evaluation of the pharmacological activity. Phytochemistry 69:2263-2269.

Salvemini D., Z. Q. Wang, P. S. Wyatt, D. M. Bourdon, M. H. Marino, P. T. Manning and M. G. Currie, (1996) Nitric oxide: a key mediator in the early and late phase of carrageenan-induced rat paw inflammation. British Journal of Pharmacology 118:829-838.

Santos V. N. C., R. A. de Freitas, F. C. Deschamps and M. W. Biavatti (2009) Ripe fruits of Bromelia antiacantha: investigations on the chemical and bioactivity profile. Revista Brasileira de Farmacognosia 19:358-365

Shahidi F. and Y. V. A. Janak Kamil (2001) Enzymes from fish and aquatic invertebrates and their application in the food industry. Trends in Food Science and Technology 12:435-464.

Spellman D., G. O'Cuinn and R. J. FitzGerald (2009) Bitterness in Bacillus proteinase hydrolysates of whey proteins. Food Chemistry 114:440-446.

Torres-Piedra M., R. Ortiz-Andrade, R. Villalobos-Molina, N. Singh, J. L. Medina-Franco, S. P. Webster, M. Binnie, G. Navarrete-Vázquez and S. Estrada-Soto (2010) A comparative study of flavonoid analogues on streptozotocin-nicotinamide induced diabetic rats: Quercetin as a potential antidiabetic agent acting via $11 \beta$-hydroxysteroid dehydrogenase type 1 inhibition. European Journal of Medicinal Chemistry 45:2606-2612

Vallés D., S. Furtado and A. M. B. Cantera (2007) Characterization of new proteolytic enzymes from ripe fruits of Bromelia antiacantha Bertol. (Bromeliaceae). Enzyme and Microbial Technology 40:409-413. 
